\title{
The Econometric Analysis of Financial Instability
}

\author{
Zehan Hou \\ College of Arts and Science, Emory University, Atlanta, Georgia, US \\ garfieldhou@163.com
}

\begin{abstract}
As the interaction between the development of financial system and the development of macro- economy is becoming stronger, the financial instability can cause the macro-economy serious damages. In this study, firstly the definition and the mechanism of action of financial instability were analyzed. Based on this, the econometric methods to measure the instability of financial were summarized.
\end{abstract}

Keywords: Financial instability; Econometric analysis; Financial system.

\section{Introduction}

In the worldwide, the development in financial area and the substantial economy are becoming more and more inseparable. While in a very long time, the instability of financial system has caused the macro economy many kinds of damages. The instability stems from the fluctuation of the economic cycle, reacts up to the real economy and cause the accumulation of financial system risk which will lead to the explosion of financial crisis [1]. In this process, the dilemma of financial institution and financial market will significantly affect consumption and the investment decision-making and damage the credit ability of financial system. However, the biggest challenge of the design of an operability framework of financial stability management is the accurate and real-time measurement of financial instability. Only with the precise measurement of financial instability can make the strategy (which can maintain the financial stability) becomes specific financial regulatory tools, and can determine the various arrangement and supervision arrangement of functional departments. Therefore, a workable measurement of financial instability is very important to the financial regulation.

\section{The definition of financial instability}

Most of economics define financial instability through the phenomenon of the instability, and the features of financial instability are asset price fluctuation, the plight of financial institutions and its adverse impact [2]. Ferguson define the financial instability from the three basic criteria:1)the rapidly fell of some important financial asset prices; 2)the ability of market financing from the domestic and foreign market were significant damaged; 3)the obvious deviation of total expenditure from the total consumption capacity the economy can provide.

As to the factors that affect the financial instability, there are four which are commonly believed by most researchers. Firstly is the change of interest rate. The information asymmetry and the adverse selection problem could cause the credit rationing problem. And the increase of interest rates can have a negative effect on a bank's balance sheet. Secondly is the increase of uncertainty. In the financial market, the mushroom of the uncertainty can cause the failure of the important financial institutions or the non-financial institutions, the economic recession, the political instability and the collapse of the stock market, and is likely to form a vicious circle. Thirdly is the balance sheet effect on asset market. The status of non-financial institutions and the bank's balance sheet is an important standard to judge the information asymmetry problem of the financial system. The deterioration of the balance sheet will make the adverse selection and moral hazard problems worse, and aggravate the financial instability. Fourthly, compared with the industrialized countries, emerging market countries face more problems that can lead to the financial instability. 


\section{The mechanism of action of financial instability}

There have been many theoretical research results showing that banking credit business has significant pro-cyclical character due to its own characteristics. The pro-cyclical character also produces certain effect on economic growth. Bernanke \& Gertler established an endogenous neoclassical business cycle dynamic model, firstly discovered the relationship between the credit market and macro-economic fluctuation, and points out its role has intensified [3].Researchers also point out that the information asymmetry characteristics of lending market leads to the pro-cyclical effect.

The credit market also has a certain particularity. Sometimes the banking industry uses the principle of credit rationing in the credit market to restrain the financing behavior in the market.

Bernanke and Gertler analyzed the indirect impact of credit markets on the real economy period from the points of view of production enterprise's balance sheet, they fixed the real business cycle model (RBC), described the transmission path of cyclical fluctuations. From the perspective of enterprise, the balance sheet reflects its financial position which will determine the subsequent investment decisions. When the cash flow and stocks of firms are sufficient, it means they can provide more investment fund. Regardless of the economic cycle under the date or up the date, bank credit acts on the enterprise investment will enlarge the economic cycle fluctuation. During the recession coupled with the tightening of monetary policy, further additional investment makes it difficult to enterprises, thereby deepening recession.

Based on the above research, Bernanke and Gertler put forward the unique concept of "financial fragility", which was measured with a net worth of the recessive borrowers' levels and this makes the concept more operable. Formed a series of theory, think the production enterprise financial situation will change the external finance premium because of the influence of the economic environment, resulting changes in subsequent additional investments which will in turn affect economic fluctuations. In this process, the function of financial system to the economic cycle is accelerating which is known as the financial accelerator principle. Under the financial accelerator effect, mortgage assets value of the periodic change can also lead to the pro-cyclical effect of the credit markets. Financial accelerator theory promotes the understanding of financial instability mechanism and the relationship between the financial market and macro-economy. The financial system controls investment and affects the macro-economic; its function is equivalent to install an accelerator to the real economy cycle. The partial equilibrium model and general equilibrium model demonstrate the credit market's important influence to the cycle of conduction path from a mathematical way.

\section{The econometric methods to measure the instability of financial}

In the empirical research, the instability of financial is a relatively generalized concept, including different stages in the evolution of the financial instability over time. Accordingly, the measurement method and means of financial instability also have differences; the econometric methods to measure the instability of financial can be divided into five categories.

\subsection{The early warning indicators measure method}

The early warning indicators are often used to identify financial distress in advance. In the early researches, simplification methods such as threshold method and multiple regression models are used to turn a series of explanatory variables into financial distress index. This kind of financial distress index is usually a binary variable and is used to measure the financial distress. Kaminsky and Reinhart firstly used the weighted average of the changes of foreign exchange reserves and changes of exchange rate to measure the extend of the foreign exchange market crisis, used the share of the cost of out of trouble in gross domestic product to measure the degree of the banking crisis. And using the method of signal noise ratio as a crisis early warning signal threshold of macroeconomic and financial variables [4]. Demirgüç-Kunt and Detragiache analyzed the macroeconomic and financial variables which can predict the bank crisis by using multivariate Logit model [5].This study firstly builds the virtual variables as the dependent variable of banking crises through four typical characteristics, and 
uses macroeconomic and financial variables (such as economic growth, trade, inflation, monetary aggregates, credit and real interest rates) as explanatory variables. The study found that the lower gross domestic product (GDP) growth rate, the high inflation and the high interest rates are usually associated with banking sector crisis. When these variables are controlled, the exchange rate depreciation and fiscal deficits no longer have explained ability for the crisis. It also finds that the volatility of capital outflow, the share of private sector credit and high credit growth in the past usually associated with high probability of a crisis. The financial distress index measurement method has problems such as the prediction period can be too short and the signal can be errored. Therefore, later studies use credit or asset price index as a financial distress early warning indicators from the viewpoint of the endogenous financial instability.

\subsection{The measurement method based on market price index}

The indicators based on market price include stocks, bonds, credit default swaps and other derivatives fluctuations or spreads, these indicators can be considered separately or be synthetic single metric. This measurement is more of a focus on the research of financial stress on the risk gathering phase, can measure risk in real time, and generally has higher frequency [6]. At the same time, the index based on the market price to some extent can reflect the joint exposure and correlation between different financial sectors. Cardarelli synthesized the financial stress index of developed economies based on the market price index of high frequency, and through the index of extremum to identify financial pressure [7]. Hakkio and Keeton summarized common phenomenon of financial pressure, based on which, through the selection of various types of indicators such as bond spreads, stock and bond yields correlation, stock market volatility, banking stocks, build a Kansas City financial pressure index reflecting the financial stress state. However, the coverage of this method may be too narrow for the risk of the financial system and there is no distinction between the present value of cash flow and the price.

\subsection{The measurement method based on the balance sheet}

The balance sheet index usually includes bank market value, non-performing loans, loan losses, and the homes and businesses items in the balance sheet, etc. The researches about the balance sheet indicators usually focus more on the measurement in the implementation stage of risk, and may also be partly focuses on the risk accumulation stage. The IMF gives the financial steady index compilation guidelines, including the concept of robust financial indicators, the definition and establishment method. While the balance sheet index such as preparation for loan losses, non-performing loan ratio and capitalization level, unless modeling in a dynamic way, it should be as the same indicator of financial distress, since a predictor index is not very appropriate. What's more, because of the lower frequency of the balance sheet indicators, there also exist some defects on the identification of financial risk.

\subsection{The analysis method for systemic financial risks}

This kind of econometric method mainly focuses on the implementation phase of the risk, which is the measurement of systemic financial risk. Mainly, there are three main methods to analysis the systemic risks: the structured analysis method, the simplification analysis method and the network analysis method. The structured analysis method for systemic financial risks mainly uses the joint probability of default or the portfolio credit risk. Lehar uses stock price time series and the balance sheet information, measures the systemic financial risks by given the joint default probability of financial institutions under the null hypothesis of the normal distribution of asset returns, and through the expected losses to calculate the overall risk contribution of a certain bank to the banking system [2]. The simplification analysis method focuses on the distribution of earnings history. The network analysis method for systemic financial risks is based on the exposure data in the balance sheet between financial institutions. Its main idea is to establish a network through the transaction data between financial institutions, employing the shape of the network to simulate the situation of risk spread, and then measure systemic risks in each network. 


\subsection{The macro stress testing method}

The macro stress testing method can be used to follow the reaction of financial system to the unusual big exogenous shock. The method's main advantage is the prospective, and the vector autoregressive (VAR) model highlights the conduction of the impact in the financial system. However, this method cannot capture the feedback between the financial system and macro economy and the main characteristic of financial distress, which is why the existing macroscopic stress tests can't replicate many of the dynamic characteristics of crisis in the past. In the financial sector assessment program (FSAP), the international monetary fund and World Bank first use the macro stress testing method to evaluate the stability of the financial system. Since then, a lot of countries' central banks including the bank of England and Austrian began to use the macro stress testing method to test the instability of their financial systems.

\section{Conclusion}

As the relationship between the financial system and economy is becoming more and more intimate, the interaction between the development of financial and macro- economy becomes stronger. The change of macro-economic environment impacts the operation of financial system, while the instability of financial system will also react upon the development of economy. Therefore, it is very important to find a workable way to test the instability of financial system, of which can accelerate economic cycle fluctuation, affects the situation of investment and employment, and eventually influence the development of economy and the society as a whole.

\section{References}

[1] Issing, O., In search of monetary stability: the evolution of monetary policy. Ssrn Electronic Journal, 2009. 68 (273): p. 1-18.

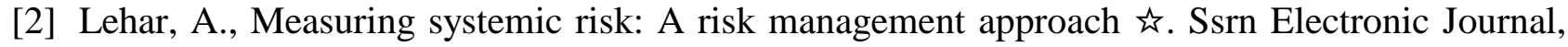
2005. 29 (10): p. 2577-2603.

[3] Bernanke, B.S. and M.L. Gertler, Monetary Policy and Asset Price Volatility. Social Science Electronic Publishing, 1999. 84 (September): p. 77-128.

[4] Kaminsky, G.L. and C.M. Reinhart, the Twin Crises: The Causes of Banking and Balance of Payments Crises. American Economic Review, 1999. 89 (3): p. 473-500.

[5] Demirgüç-Kunt, A. and E. Detragiache, the Determinants of Banking Crises in Developing and Developed Countries. Imf Staff Papers, 1998. 45 (1): p. 3-3.

[6] Borio, C. and M. Drehmann, Assessing the Risk of Banking Crises. Social Science Electronic Publishing, 2009. 29 (4): p. 257\&ndash; 261.

[7] Cardarelli, R., S. Elekdag, and S. Lall, Financial stress and economic contractions. Journal of Financial Stability, 2011.7 (2): p. 78-97. 